\title{
Erratum: A dual leucine kinase-dependent axon self-destruction program promotes Wallerian degeneration
}

Bradley R Miller, Craig Press, Richard W Daniels, Yo Sasaki, Jeffrey Milbrandt \& Aaron DiAntonio

Nat. Neurosci. 12, 387-389 (2009); published online 15 March 2009; corrected after print 15 May 2009

In the version of this article initially published, the abbreviation DLK was omitted from the abstract. The second sentence of the abstract should be "We found that dual leucine kinase (DLK) promoted degeneration of severed axons in Drosophila and mice, and that its target, c-Jun N-terminal kinase, promoted degeneration locally in axons as they committed to degenerate". The error has been corrected in the HTML and PDF versions of the article.

\section{Erratum: A precise form of divisive suppression supports population coding in the primary visual cortex}

Sean P MacEvoy, Thomas R Tucker \& David Fitzpatrick

Nat. Neurosci. 12, 637-645 (2009); published online 26 April 2009; corrected after print 6 May 2009

In the version of this article initially published, the gray curve in Figure $1 \mathrm{j}$ was shifted to the left. The corrected figure is shown below. The error has been corrected in the HTML and PDF versions of the article.

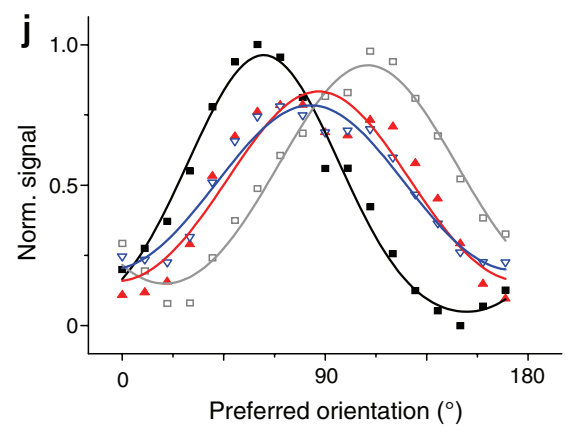

\section{Erratum: Selective regulation of long-form calcium-permeable AMPA receptors by an atypical TARP, $\gamma-5$}

David Soto, Ian D Coombs, Massimiliano Renzi, Marzieh Zonouzi, Mark Farrant \& Stuart G Cull-Candy

Nat. Neurosci. 12, 277-285 (2009); published online 22 February 2009; corrected after print 16 March 2009

In the version of this article initially published, the bar graphs in Figure 7c and 7d were misaligned. The error has been corrected in the HTML and PDF versions of the article.

\section{Corrigendum: Links from complex spikes to local plasticity and motor learning in the cerebellum of awake-behaving monkeys}

Javier F Medina \& Stephen G Lisberger

Nat. Neurosci. 11, 1185-1192 (2008); published online 21 September 2008; corrected after print 15 January and 30 April 2009

In the version of this article initially published, two citations were inadvertently omitted. To correct this, the following two sentences were added to the second paragraph of the introduction, following the sixth sentence. "One line of work has supported the theory by demonstrating that arm movement errors evoke complex spikes ${ }^{51,52}$ and that subsequent learned changes in motor behavior are associated with suitable changes in simple spike responses ${ }^{51}$. This work demonstrates a strong correlation, but stops short of showing cause-and-effect links between individual complex spikes, changes in simple spikes and behavioral learning." Two references were also added to the reference list as follows:

51. Gilbert, P.F. \& Thach W.T. Purkinje cell activity during motor learning. Brain Res. 128, 309-328 (1977).

52. Ojakangas C.L \& Ebner T.J. Purkinje cell complex and simple spike changes during a voluntary arm movement learning task in the monkey. J. Neurophysiol. 68, 2222-2236 (1992).

In addition, the second sentence of the abstract should read "Many elements of this hypothesis have been supported by prior experiments, and correlations have been found between complex spikes, simple-spike plasticity and behavior during the learning process." The errors have been corrected in the HTML and PDF versions of the article. 